\title{
Can Aerobic Training Restore the Vascular Dysfunction Induced by Intrauterine Growth Restriction? Evidences from Experimental Studies
}

\author{
Sebastião Donato Silva Junior ${ }^{1}$, Ph.D and Vanessa Oliveira*2, Ph.D \\ ${ }^{1}$ Pharmacology Department, Carver College of Medicine, USA \\ ${ }^{2}$ Department of Internal Medicine, Carver College of Medicine, USA \\ *Corresponding author: Vanessa Oliveira, Department of Internal Medicine, Carver College of Medicine, IA, USA
}

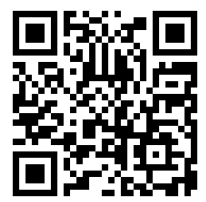

\section{ARTICLE INFO}

Received: 慧 February 01, 2019

Published: 幽 February 13, 2019

Citation: Sebastião Donato Silva Junior, Ph.D, Vanessa Oliveira, Ph.D. Can Aerobic Training Restore the Vascular Dysfunction Induced by Intrauterine Growth Restriction? Evidences from Experimental Studies. Biomed J Sci \& Tech Res 14(3)-2019. BJSTR. MS.ID.002561.
ABSTRACT

Aerobic training is used as a non-pharmacological treatment to improve vascular function in cardiometabolic conditions, but its potential effects in minimize the deleterious adaptations induced by IUGR in log-term are poor investigated. In this mini review we sought to briefly highlight how aerobic training seems to counteract the effects of IUGR in the vascular function.

Keywords: Aerobic Training; Exercise; Intrauterine Growth Restriction; Fetal Programming; Vascular Function

\section{Introduction}

\section{Fetal Programming - Brief Concepts}

The casual association between abnormalities in the fetal development (eg., intrauterine growth restriction (IUGR) or prematurity) and the incidence of chronic conditions (eg., hypertension, coronary artery disease and stroke) in long-term was first proposed by Professor Barker [1,2]. These observations led to postulate the Fetal Programming Hypothesis or Barker`s Hypothesis. Fetal programming takes place during critical windows of intrauterine development inducing permanent adaptations in target organs $[3,4]$. Its etiology is multifactorial and complex. Stressor agents including, poor maternal nutrition during pregnancy, glucorticoides exposure, preeclampsia, hypoxia, and advanced maternal age have been described as potential drivers to programming the cardiovascular function in the offspring [5-9].

\section{How does Fetal Programming Modulate the Endothelial Function?}

IUGR can compromise the full development of target organs (eg., brain, kidney, heart, and blood vessels) directly involved in the cardiovascular control [5,8,10-12]. Humans and animals submitted to IUGR show deleterious changes in vascular function, as increased vasoconstrictor response and impairment in modulatory function of endothelium, resulting in reduced vasodilatation endothelium-dependent [13-17]. The mechanisms already described showed increase vasoconstriction to endotelin-1 in mesenteric arteries as well as hyperreactivity to Angiotensin II (Ang II) in both in the microvasculature in vivo in situ and in isolated aortic rings $[16,18,19]$. The increase in the Ang II response is at least in part due to reduction in the expression of AT2 receptors of Ang II [18]. Furthermore, reduction in nitric oxide enzyme activity (NOS), and increased in eNOSthr495 phosphorylation were also reported, resulting in lower nitric oxide production $[17,20]$. Higher reactive oxygen species (ROS) concentration due to reduction in antioxidant enzymes and higher activity of pro oxidative enzymes also collaborate to decrease the NO bioavailability [18].

Factors involved in the endothelium repair, as the endothelial progenitor cells (EPCs) are also compromised under IUGR conditions in both humans and animals. Ligi et al reported lower func- 
tional capacity of EPCs extracted from umbilical cord in premature neonates [21]. Consistently, we found in adult IUGR rats reduction in the number of EPCs-forming colonies and increased number of senescent cells not only in the peripheral blood but also in the bone marrow compartment [20]. These findings evidence that IUGR can program EPCs properties early in life and its effect persist into adulthood.

\section{Is the Aerobic Training an Effective Tool to Abolish the Effects of IUGR in the Vasculature?}

Despite aerobic training has been used as a safety and powerful non-pharmacological treatment in chronic conditions, including hypertension, diabetes and obesity [22,23], its potential effects on the outcomes induced by IUGR are not widely investigated. Given that IUGR might be an additional risk factor for developing cardiometabolic conditions in long-term and that aerobic training drives positive effects in those conditions, it is plausible hypothesize that aerobic training could counteract the deleterious effects induced by IUGR in the vasculature. In fact, we observed that male adult IUGR rats submitted to aerobic training protocol ( 5 days per week, 60 minutes per day, 10 weeks of low-moderate aerobic training between $50-60 \%$ of their maximal capacity) reduced the high vasoconstrictor response to Ang II in aortic rings. This effect was mediated in part due to increase in the AT2 receptors expression [18]. Additionally, aerobic training normalized the expression of p47phox subunit of NADPH oxidase and upregulated the manganes isoform of superoxide dismutase enzyme contributing to lower the ROS concentration in this vascular bed [18]. Later, Reyes et al also reported that in males aerobic training improved the vasodilatation mediated by the endothelium-derived hyperpolarization factor in gastrocnemius arteries. However, no effects on the vasculature were observed in female IUGR submitted to the same aerobic training protocol [8] This interesting observation in females led us to hypothesize that the effects of aerobic training seem to be sex-specific in rats submitted to IUGR.

\section{Conclusion}

Fetal programming has a high potential to promote deleterious cardiovascular effects in long-term. However, the life style, a modifiable factor, can prevent or reduce those negative outcomes. Low-moderate aerobic training seems to be an effective tool to restore vascular alterations induced by IUGR at least in male offspring, reducing the risk to develop cardiovascular events in longterm.

\section{References}

1. Barker DJ, Bull AR, Osmond C, Simmonds SJ (1990) Fetal and placental size and risk of hypertension in adult life. BMJ 301(6746): 259-262.

2. Barker DJ, Osmond C, Simmonds SJ, Wield GA (1993) The relation of small head circumference and thinness at birth to death from cardiovascular disease in adult life. BMJ 306(6875): 422-426.

3. Gluckman PD, Hanson MA (2004) Living with the past: evolution, development, and patterns of disease. Science 305(5691): 1733-1736.
4. Gluckman PD, Hanson MA, Pinal C (2005) The developmental origins of adult disease. Maternal \& child nutrition 1(3): 130-141.

5. Torrens C, Hanson MA, Gluckman PD, Vickers MH (2009) Maternal undernutrition leads to endothelial dysfunction in adult male rat offspring independent of postnatal diet. The British journal of nutrition 101(1): 27-33.

6. Belkacemi L, Jelks A, Chen CH, Ross MG, Desai M (2011) Altered placental development in undernourished rats: role of maternal glucocorticoids. Reproductive biology and endocrinology 9: 105.

7. Nahum Sacks K, Friger M, Shoham Vardi I, Spiegel E, Sergienko R, et al. (2018) Prenatal exposure to preeclampsia as an independent risk factor for long-term cardiovascular morbidity of the offspring. Pregnancy hypertension 13: 181-186.

8. Reyes LM, Morton JS, Kirschenman R, DeLorey DS, Davidge ST (2015) Vascular effects of aerobic exercise training in rat adult offspring exposed to hypoxia-induced intrauterine growth restriction. The Journal of physiology 593(8): 1913-1929.

9. Cooke CM, Shah A, Kirschenman RD, Quon AL, Morton JS, et al. (2018) Increased susceptibility to cardiovascular disease in offspring born from dams of advanced maternal age. The Journal of physiology 596(23): 5807-5821.

10. Hunter DS, Hazel SJ, Kind KL, Owens JA, Pitcher JB, et al. (2016) Programming the brain: Common outcomes and gaps in knowledge from animal studies of IUGR. Physiology \& behavior 164(Pt A): 233-248.

11. Murano Y, Nishizaki N, Endo A, Ikeda N, Someya T, et al. (2015) Evaluation of kidney dysfunction and angiotensinogen as an early novel biomarker of intrauterine growth restricted offspring rats. Pediatric research 78(6): 678-682.

12. Jonker SS, Kamna D, Loturco D, Kailey J, Brown LD (2018) IUGR impairs cardiomyocyte growth and maturation in fetal sheep. The Journal of endocrinology 239: 253-265.

13. Leeson CP, Kattenhorn M, Morley R, Lucas A, Deanfield JE (2001) Impact of low birth weight and cardiovascular risk factors on endothelial function in early adult life. Circulation 103(9): 1264-1268.

14. Holemans K, Gerber R, Meurrens K, De Clerck F, Poston L, et al. (1999) Maternal food restriction in the second half of pregnancy affects vascular function but not blood pressure of rat female offspring. The British journal of nutrition 81(1): 73-79.

15. Ozaki T, Nishina H, Hanson MA, Poston L (2001) Dietary restriction in pregnant rats causes gender-related hypertension and vascular dysfunction in offspring. The Journal of physiology 530 (Pt 1): 141-152.

16. Ceravolo GS, Franco MC, Carneiro Ramos MS, Barreto Chaves ML, Tostes RC, et al. (2007) Enalapril and losartan restored blood pressure and vascular reactivity in intrauterine undernourished rats. Life sciences 80(8): 782-787.

17. Franco Mdo C, Fortes ZB, Akamine EH, Kawamoto EM, Scavone C, de Britto LR, et al. (2004) Tetrahydrobiopterin improves endothelial dysfunction and vascular oxidative stress in microvessels of intrauterine undernourished rats. The Journal of physiology 558(Pt 1): 239-248.

18. Oliveira V, Akamine EH, Carvalho MH, Michelini LC, Fortes ZB, et al. (2014) Influence of aerobic training on the reduced vasoconstriction to angiotensin II in rats exposed to intrauterine growth restriction: possible role of oxidative stress and AT2 receptor of angiotensin II. PLoS One 9(11): e113035.

19. Bourque SL, Gragasin FS, Quon AL, Mansour Y, Morton JS, et al. (2013) Prenatal hypoxia causes long-term alterations in vascular endothelin-1 function in aged male, but not female, offspring. Hypertension 62(4): 753-758.

20. Oliveira V, De Souza LV, Fernandes T, Junior SDS, De Carvalho MHC, et al. (2017) Intrauterine growth restriction-induced deleterious adaptations in endothelial progenitor cells: possible mechanism to 
impair endothelial function. Journal of developmental origins of health and disease 8(6): 665-673.

21. Ligi I, Simoncini S, Tellier E, Vassallo PF, Sabatier F, Guillet B, et al. (2011) A switch toward angiostatic gene expression impairs the angiogenic properties of endothelial progenitor cells in low birth weight preterm infants. Blood 118(6): 1699-1709.

\section{ISSN: 2574-1241}

DOI: 10.26717.BJSTR.2019.14.002561

Vanessa Oliveira. Biomed J Sci \& Tech Res

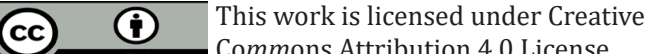

Submission Link: https://biomedres.us/submit-manuscript.php
22. Pescatello LS, Mac Donald HV, Lamberti L, Johnson BT (2015) Exercise for Hypertension: A Prescription Update Integrating Existing Recommendations with Emerging Research. Current hypertension reports $17(11): 87$

23. Swift DL, Mc Gee JE, Earnest CP, Carlisle E, Nygard M, et al. (2018) The Effects of Exercise and Physical Activity on Weight Loss and Maintenance. Progress in cardiovascular diseases 61(2): 206-213.

\begin{tabular}{ll} 
BIOMEDICAL & Assets of Publishing with us \\
RESEARCHES & - Global archiving of articles \\
\hline ISSN: $2574-1241$ & - Immediate, unrestricted online access \\
\hline
\end{tabular}

